\title{
The Clinicoanatomic Uniqueness of the Human Pyramidal Tract and Syndrome
}

\author{
Ricardo de Oliveira-Souza \\ D'Or Institute for Research \& Education (IDOR) and Federal University of the State of Rio de Janeiro, Brazil
}

\section{Article Info}

\section{Article Notes}

Received: November 28, 2016

Accepted: February 02, 2017

\section{*Correspondence:}

Ricardo de Oliveira-Souza

Rua Diniz Cordeiro, $30 / 2^{\circ}$ andar

Rio de Janeiro, RJ, Brazil

Email: rdeoliveira@gmail.com

(c) 2017 de Oliveira-Souza R. This article is distributed under the terms of the Creative Commons Attribution 4.0 International License

\section{Keywords}

Brain reorganization

Erect bipedalism

Extrapyramidal system

Human prepyramidal system

Pyramidal tracts

Sign of Babinski

Spastic hemiplegia

\begin{abstract}
The chief goal of the present review is to present clinicoanatomic evidence that, (i) in contrast to most vertebrates, spastic hemiplegia in man is a symptom of damage to the pyramidal tracts, and (ii) although extrapyramidal structures are often injured as a contingency of anatomical proximity in cases of pyramidal damage, the extrapyramidal system plays no role in the production of human spastic hemiplegia. The views herein discussed reconcile several apparent incongruences concerning the pathophysiology of the human pyramidal syndrome. From a neurobiological perspective, the progressive commitment to occasional, habitual and obligate bipedalism fostered a profound internal reorganization of the mammalian brain at the early stages of human phylogenesis. The major anatomical counterpart of this reorganization was an unprecedented increase of the ansa lenticularis fiber system, which ultimately redirected the product of subcortical motor activity up to the motor cortices from which the pyramidal tracts originate. In this sense, while the fundamental motor organization of vertebrates is represented by the extrapyramidal system, the dominant motor plan in humans is uniquely represented by the prepyramidal system.
\end{abstract}

\section{Introduction}

The goal of this review is to present clinicoanatomical evidence that the human motor system is unique in its anatomical and functional organization. This uniqueness is captured by the concept of "prepyramidal system", which is elaborated at the end of this review. The validity of the concept of prepyramidal system, which fully applies to humans only, has two broad implications. Firstly, when the pyramidal tracts are bilaterally damaged in the cerebral hemispheres or brainstem the syndrome of double (or bilateral) hemiplegia ensues. Indeed, severe and complete bilateral hemiplegia equals the lockedin syndrome ${ }^{1}$; secondly, contrary to prevailing knowledge ${ }^{2}$, associated damage to extrapyramidal structures is irrelevant for the production of the full syndrome of spastic hemiplegia in man. For the purposes of the present review, the pyramidal tract is defined by the collection of fibers that originate in the cerebral cortex and pass through the medullary pyramids without interruption in their way to the motor neuron pools of the spinal $\operatorname{cord}^{3}$. This definition includes the aberrant fascicles with a similar cortical origin that end in the motor apparatus of the brainstem ${ }^{4}$. A comprehensive reference list may be found in previous related articles ${ }^{5,6}$.

\section{Spastic hemiplegia and pyramidal tract damage}

Elsewhere I have shown that between 1877 and 2007 fewer than 50 clinicoanatomic reports on hemiplegia were published from which 
reliable clinicoanatomic inferences could be drawn ${ }^{6}$. Over the same period, I was able to unearth very few cases of hemiplegia with intact pyramidal tracts and not even a single case of degeneration of the pyramidal tracts without at least one of the four cardinal signs of the pyramidal syndrome, namely, paralysis, spasticity, hyperactive phasic muscle ("tendon") reflexes, and the sign of Babinski. The rare cases of hemiplegia with intact pyramidal tracts were accounted for by destruction of aberrant pyramidal tract (PyrT) tract fibers in the tegmentum ${ }^{7}$, hemidystonia misdiagnosed as spastic hemiplegia ${ }^{8,9}$, or joint fixity due to long-standing immobility from various causes ${ }^{10,11}$. The only genuine instance of paralysis with intact pyramidal tracts was described as the "primary motor cortex isolation syndrome"12.

Notwithstanding the fragmentary nature of the clinicopathologic evidence, sufficient information exists to allow a formulation of the clinical picture produced by PyrT injury in man. Severe contralateral paralysis comprises the essential symptom of an injury of the PyrT. When the injury results from a static lesion, as is in capsular stroke, some recovery is the rule ${ }^{13}$; indeed, recovery may be surprisingly complete ${ }^{14,15}$ or nearly so ${ }^{16}$ to the point of allowing a return of the patient to his previous activities. In cases in which recovery is only partial, the paralysis is initially flaccid and arreflexic, yet the plantar reflex is often extensor at this time. In a few days to a few weeks, flaccidity gradually gives way to spasticity at the same time that the tendon reflexes reappear and eventually become hyperactive, as indicated by foot clonus and Hoffmann's sign ${ }^{17}$. These phenomena are most evident on standing and walking as the WernickeMann attitude. In cases in which damage to the pyramidal tracts follows a subacute or slowly progressive course, such as in primary lateral sclerosis, the onset of the pyramidal syndrome is gradual, but all the cardinal signs of the pyramidal syndrome eventually appear ${ }^{18}$. Thus, whereas paralysis reflects a loss of pyramidal function, being thus a deficit symptom, the other three manifestations (the sign of Babinski, hyperactive tendon jerks, and spasticity) are indicative of a release of the segmental mechanisms from pyramidal modulation. This assertion is demonstrated by the fact that a bilateral injury of the pyramidal tracts produces essentially the same clinical motor syndrome observed in transverse sections of the spinal cord ${ }^{19-21}$.

The mechanisms of recovery from hemiplegia need not concern us here, except for the following point: when the contralesional so far intact pyramidal tract is also injured, loss of function in the previously recovered side ensues ${ }^{22-24}$. In these cases, a new hemiplegia is added to the older one, both combining to make up a locked-in state. This phenomenon indicates that whatever the nature of the reorganization that mediates motor recovery, it is ultimately expressed through the contralesional intact PyrT.
The most important conclusion fostered by these studies is that the human pyramidal syndrome reflects pyramidal tract damage with no need to invoke collateral damage to other motor structures (e.g., reticular formation and reticulospinal tracts) to explain the cardinal symptoms of spastic hemiplegia.

Uncertainties on the validity of the concept of pyramidal syndrome

The view expressed in the preceding section dominated clinical neurology from the last quarter of the nineteenth century approximately up to World War II. Pari passu with the rise of experimental neurology, the concept of extrapyramidal system increasingly competed with the pyramidal concept as the substrate of postural-locomotor mechanisms. In fact, the extrapyramidal concept originally designated the collection of tegmentospinal pathways that run in parallel with the pyramidal tracts and mediated associated movements in $\operatorname{dogs}^{5}$. These movements provided the indispensable postural adjustments to the temporally fractionated ("skilled") movements carried out by the faciorespiratory, fingers and toes muscles. This view eventually implied that most symptoms of the pyramidal syndrome were actually produced by damage to extrapyramidal structures rather than to the pyramidal tracts proper. Although this claim is valid for nonhuman species, it has never shown to be true for human patients; however, it eventually won the dispute and was assimilated by clinical neurology to varying degrees. At least since the 1970's, most textbooks and articles have taken as established fact that the phenomenon of spastic hemiplegia would largely result either from extrapyramidal injury at several possible levels of the forebrain and brainstem or from a release of extrapyramidal pathways from higherorder centers. The central paradox may be stated as follows: while clinicoanatomic evidence has shown that damage to the pyramidal tracts is necessary and sufficient to produce spastic hemiplegia in $\operatorname{man}^{6}$, an ever-growing collection of experiments on rodents, carnivores and nonhuman primates appears to demonstrate exactly the opposite ${ }^{25}$.

The human motor system is distinct in its anatomical and functional organization from the motor system of the other vertebrates

On closer inspection, the way out of this conundrum is provided by the obvious interspecies differences on the neuroanatomical organization of the motor systems of vertebrates ${ }^{26}$. As a rule, the mode of posture and locomotion are the main correlates of the motor architecture of a given species. Indeed, the extrapyramidal system is the dominant motor system of most vertebrates, a dominance that is intimately related to the perpendicular orientation of their body axes in relation to gravity ${ }^{27}$. Erect bipedalism, the obligate mode of standing and walking of 
our species, affords human beings a unique position in this regard $^{28}$. It has been the defining biological characteristic of hominins ${ }^{29}$ and possibly also the prime mover that drove the reorganization of the human brain at the homininchimpanzee split ${ }^{30}$.

Compared to the other mammals, the human motor organization is distinguished by an unprecedented increase in bulk of (i) the pyramidal tracts ${ }^{31,32}$, (ii) the pallidothalamic projections to the motor cortices ${ }^{33}$ and (iii) the propriospinal system ${ }^{34}$, as well as (iv) by a decrease in the overall bulk of tegmentospinal projections, chiefly the reticulospinal, vestibulospinal, tectospinal, and rubrospinal tracts $^{35-38}$. In humans, the product of subcortical motor activity must thus be reoriented upwards, as indicated by the remarkable volume of the human ansa lenticularis, lato sensu ${ }^{39}$. The ansa lenticularis system then funnels the motor activity of higher-order cortical areas which, ultimately project in an orderly fashion to the putamen, pallidum, motor thalamus and motor cortices ${ }^{40}$. The human pyramidal tracts embody the product of the sequential and simultaneous activity of several cortico-subcorticocortical loops which are ultimately translated into behavior through a direct innervation of the motoneuron pools of the brainstem and spinal cord.

This architecture contrasts with the fundamental vertebrate motor blueprint, in which the tegmentospinal tracts play the chief role in movement. These tracts receive afferents from the cerebral cortex and basal ganglia, and run downwards in parallel with the pyramidal tracts to terminate in the brainstem and spinal cord motor neurons ${ }^{41,42}$. Accordingly, whereas bilateral damage to the pyramidal tracts produces a severe bilateral spastic hemiplegia in humans ${ }^{19,20}$, in monkeys, for example, it results in loss of individual movements of the fingers and toes without impairing postural-locomotor mechanisms ${ }^{43}$. Experimental damage to the descending brainstem pathways leaving the pyramidal tracts intact, in contrast, renders nonhuman primates severely disabled, an indication of the importance of the tegmentospinal tracts for their motor behavior ${ }^{44}$. In keeping with the scarcity of the tegmentospinal tracts in humans, patients with bilateral pyramidal tract damage are rendered incapable not only of moving their extremities, but the large axial and appendicular muscles as well ${ }^{45,46}$.

\section{The human prepyramidal system (Figure)}

Tradition has loosely referred to the basal ganglia and their related pathways as the "extrapyramidal system". This view reflects a long-held tradition in clinical neurology that equates abnormal involuntary movements and postures (AIMP) with the basal ganglia and pathways. Although this may be valid for most vertebrates, it certainly does not apply to humans. This is so due to the simple fact that, except for a few critical reticulospinal projections, the human extrapyramidal pathways are rather reduced in bulk. Their chief functional role concerns the promotion of faciorespiratory synergies, especially automatic breathing ${ }^{47}$ and the extreme emotional expressions of laughing and crying ${ }^{48}$. Moreover, in at least one case
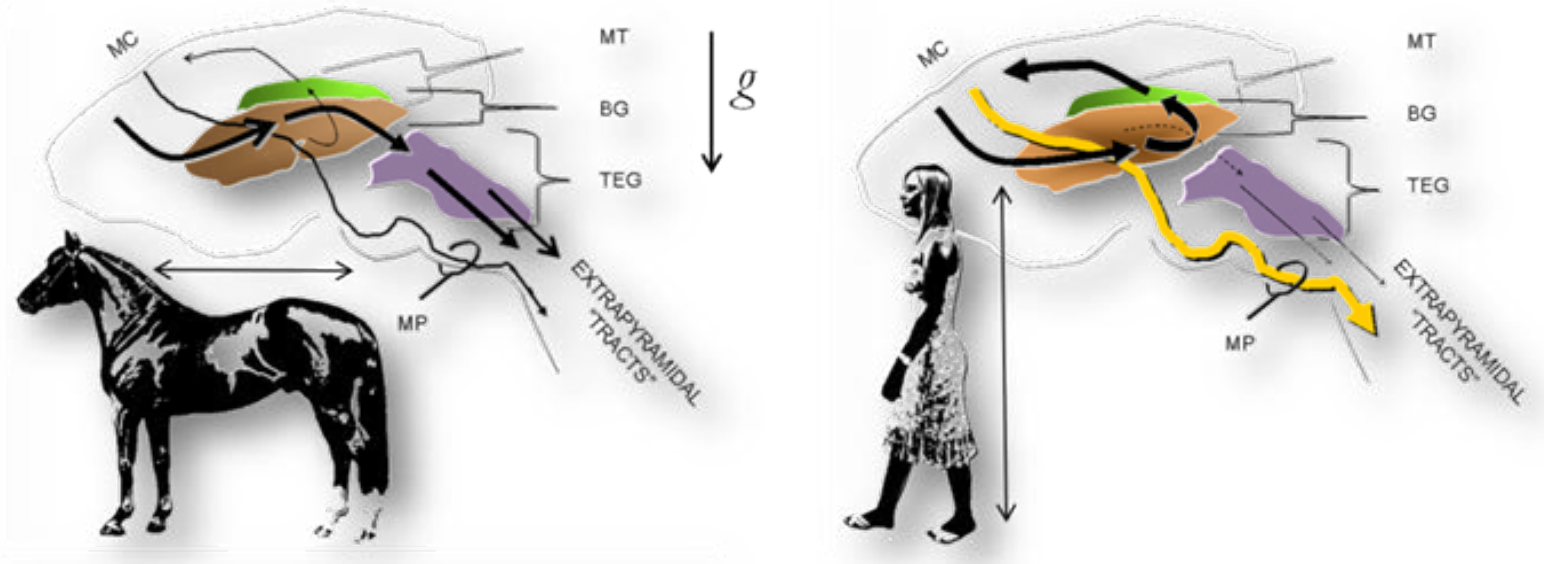

Figure 1: The fundamental organization of the motor system in vertebrates and man. Left. In most vertebrates, including nonhuman primates, the extrapyramidal and pyramidal fiber systems run in parallel from the motor cortices (MC) to the motoneuron pools of the brainstem and spinal cord. The extrapyramidal system consists of a series of cortical projections interrupted at the basal ganglia (BG) and brainstem tegmentum (TEG) whence tegmentospinal projections originate (chiefly, reticulospinal, vestibulospinal, tectospinal and rubrospinal tracts). Right. The adoption of obligate erect bipedalism in humans was paralleled by a profound cerebral reorganization. These changes are reflected in an unprecedented increase in the ansa lenticularis fiber system. The ansa directs the projections from widespread cortical areas into the thalamic motor nuclei $(\mathrm{mt})$, which project back to the motor cortices that give rise to the pyramidal tracts. The increase in the pyramidal tracts (MP), in turn, is paralleled by an unprecedented decrease of the descending motor (extrapyramidal) pathways. Note the perpendicular and parallel orientations of the quadrupedal and human body axes (arrows), respectively, in relation to gravity (g). mp: medullary pyramids. 
extensive destruction of the pontomedullary tegmentum leaving the pyramidal tracts intact did not produce any motor impairment of trunk or limbs ${ }^{49}$. Because, as demonstrated by clinicoanatomical studies, the parallel extrapyramidal pathways perform a limited, albeit vital (automatic respiration), role in human movement, one must look for alternative pathways for the insertion of the workings of the basal ganglia into motor behavior. Several independent lines of evidence indicate that the pyramidal tracts are the pathways through which the basal ganglia express their activity. One such compelling evidence is provided by the post-hemiplegic disorders of movement. Choreoathetosis and dystonia are well-known phenomena in some patients with strokes of the striothalamocapsular region ${ }^{50}$. These AIMP become clinically apparent if at least some fibers of the pyramidal tracts are spared in injuries of the internal pallidal segment or its thalamic recipients. If the pyramidal tracts are completely destroyed, the classical hemiplegic attitude sets up and AIMP are not seen ${ }^{51}$. Another converging line of evidence concerns the opposite situation, namely, the conversion of a previous AIMP, such as parkinsonian tremor, into the stereotyped WernickeMann attitude by pyramidal tract damage, again indicating that the abnormal movement or posture was relayed to the segmental motor neuron pools through those tracts.

\section{Conclusions}

Knowledge on the anatomical and functional organization of the human pyramidal tracts is surprisingly fragmentary. From our current perspective, the early ideas on the clinical correlates of PyrT damage remains valid today as when they were first enunciated. The full-blown pyramidal syndrome in man reflects a complete lesion of the PyrT at some point in the contralateral cerebral hemisphere or brainstem. The human pyramidal tracts are as distinctive as the adoption of erect bipedalism early in hominin evolution. The phylogenetic changes in the functional anatomy of the pyramidal tracts were concatenated with changes in related anatomical and functional systems, which massively redirect the product of subcortical motor nuclei to the motor cortical areas from which the pyramidal tracts originate. The cerebral organization of movement in man is distinguished from that of the other mammals by a unique prepyramidal organization. These claims are currently amenable to direct investigation with the modern techniques of neuroimaging and electrophysiology ${ }^{52}$.

\section{Acknowledgements}

The author is indebted to Professor Omar da Rosa Santos (Federal University of the State of Rio de Janeiro) for institutional support, and to Mr. José Ricardo Pinheiro and Mr. Jorge Baçal (in memoriam), librarians of the Oswaldo Cruz Institute, Rio de Janeiro, for their invaluable help in the retrieval of rare articles and books.

\section{References}

1. de Oliveira-Souza R. Motor hemiplegia and the cerebral organization of movement in man II. The myth of the human extrapyramidal system. Arq Neuropsiquiatr. 1989; 47: 16-27.

2. Ropper AH, Samuels MA, Klein JP. Adams and Victor's Principles of Neurology tenth edition. New York: McGraw-Hill. 2014.

3. Verhaart WJC. The anatomy of the pyramidal tract. Folia Psychiatr Neurol Neurochir. 1953; 56: 923-942.

4. Iwatsubo T, Kuzuhara S, Kanemitsu A, et al. Corticofugal projections to the motor nuclei of the brainstem and spinal cord in humans. Neurology. 1990; 40: 309-312.

5. de Oliveira-Souza R. The human extrapyramidal system. Med Hypotheses. 2012; 79: 843-852.

6. de Oliveira-Souza R. Damage to the pyramidal tracts is necessary and sufficient for the production of the pyramidal syndrome in man. Med Hypotheses. 2015; 85: 99-110.

7. Kao CD, Guo WY, Chen JT, Wu et al. MR findings of decerebrate rigidity with preservation of consciousness. Am J Neuroradiol. 2006; 27: 1074-1075.

8. Bielschowsky M. Ueber Hemiplegie bei intakter Pyramidenbahn Ein Beitrag zur Kenntnis des Schichtungsplanes der Grosshirnrinde. J Psychol Neurol (Leipz). 1916; 22: 225-265.

9. Oppenheimer DR. A case of striatal hemiplegia. J Neurol Neurosurg Psychiatry. 1967; 30: 134-139.

10. Babinski J. Sur une forme de paraplégie spasmodique consécutive à une lésion organique sans dégénération du système pyramidal. Bull et Mém Société Méd Hôp Paris. 1899; 16: 342-354.

11. Yakovlev PI. Paraplegia in flexion of cerebral origin. J Neuropathol Exp Neurol. 1954; 13: 267-296.

12. Sakai K, Kojima E, Suzuki M, et al. Primary motor cortex isolation complete paralysis with preserved primary motor cortex. J Neurol Sci. 1998; 155: 115-119.

13. Twitchell TE. The restoration of motor function following hemiplegia in man. Brain. 1951; 74: 443-480.

14. Bucy PC. The central neural mechanism controlling movement with special reference to the pyramidal tract. Acta Neurochir Wien. 1964; 11: 731-738.

15. Marinesco G. Contribution à l'étude du mécanisme des mouvements volontaires et des fonctions du faisceau pyramidal. Sem Méd. 1903; 40: $325-329$

16. Barré JA. Le syndrome pyramidal déficitaire. Rev Neurol (Paris). 1937; 67: 1-40.

17. Dejerine J. Sémiologie des Affections du Système Nerveux. Paris Masson et Cie. 1914.

18. Fisher CM. Pure spastic paralysis of corticospinal origin. Can J Neurol Sci. 1977; 4: 251-258.

19. Jagiella WM, Sung JH. Bilateral infarction of the medullary pyramids in humans. Neurology. 1989; 39: 21-24.

20. Meyer JS, Herndon RM. Bilateral infarction of the pyramidal tracts in man. Neurology. 1962; 12: 637-642.

21. Jørgensen E0. Spinal man after brain death. Acta Neurochir (Wien). 1973; 28: 259-273

22. Fisher CM. Bilateral occlusion of basilar artery branches. J Neurol Neurosurg Psychiatry. 1977; 40: 1182-1189.

23. Fisher CM. Concerning the mechanism of recovery in stroke 
hemiplegia. Can J Neurol Sci. 1992; 19: 57-63.

24. Moon SY, Kim HY, Chung CS. A sequential bilateral medial medullary infarction separated by 4 months. Neurology. 2002; 59: 1814-1815.

25. Denny-Brown D. The Cerebral Control of Movement Springfield, Ill. Charles C Thomas. 1966.

26. DeMeyer W, Ross AT. The syndrome of complete interruption of the corticospinal tract in the brainstem of man. A case report and comparison with the effects of pyramidotomy in the monkey. Trans Am Neurol Assoc. 1959; 84: 18-23.

27. Skoyles JR. Human balance the evolution of bipedalism and dysequilibrium syndrome. Med Hypotheses. 2006; 66: 1060-1068.

28. Harcourt-Smith WEH. Origin of bipedal locomotion. In W Henke and I Tattersall (Editors). Handbook of Paleoanthropology volume 3 second edition: Phylogeny of Hominins. Berlin: Springer Verlag. 2015.

29. Klein R. The Human Career. Human Biological and Cultural Origins third edition. University of Chicago Press. 2009.

30. Holloway RL. The evolution of the hominid brain. In W Henke I. Tattersall (Editors). Handbook of Paleoanthropology volume 3 second edition: Phylogeny of Hominins. Berlin: Springer Verlag. 2015.

31. Nathan PW, Smith MC, Deacon P. The corticospinal tracts in man Course and location of fibres at different segmental levels. Brain. 1990; 113: 303-324.

32. Schoen JHR. The corticofugal projection on the brain stem and spinal cord in man. Psychiat Neurol Neurochir. 1969; 72: 121-128.

33. Gebbink TB. Structure and Connections of the Basal Ganglia in Man. Assen: van Gorcum \& Co. 1967.

34. Nathan PW, Smith MC. Fasciculi proprii of the spinal cord in man Review of present knowledge. Brain. 1958; 82: 610-618.

35. Nathan PW, Smith MC, Deacon P. Vestibulospinal, reticulospinal and descending propriospinal fibers in man. Brain. 1996; 119: 1809-1833.

36. Nudo RJ, Masterton RB. Descending pathways to the spinal cord A comparative study of 22 mammals. J Comp Neurol. 1988; 277: 53-79.

37. Schoen JHR. Comparative aspects of the descending fibre systems in the spinal cord. Prog Brain Res. 1964; 11: 203-222.

38. Sie PG. Localization of fibre systems within the white matter of the medulla oblongata and the cervical cord in man. Leiden: Eduard Ijdo. 1956.
39. Nauta WJH, Mehler WR. Projections of the lentiform nucleus in the monkey. Brain Res. 1966; 1: 3-42.

40. Parent A, Hazrati LN. Functional anatomy of the basal ganglia. I. The cortico-basal ganglia-thalamo-cortical loop. Brain Res Rev. 1995; 20: 91-127.

41. Takada M, ZK Li, Hattori T. Long descending direct projection from the basal ganglia to the spinal cord: a revival of the extrapyramidal concept. Brain Res. 1987; 436: 129-135.

42. ten Donkelaar HJ, Binder MD, Hirokawa N, et al. Evolution of motor systems corticospinal, reticulospinal rubrospinal and vestibulospinal systems: In: MD Binder, N Hirokawa, U Windhorst (Editors): Encyclopedia of Neuroscience. New York: Springer. 2009.

43. Lawrence DG, Kuypers HGJM. The functional organization of the motor system in the monkey. I. The effects of bilateral pyramidal lesions. Brain. 1968; 91: 1-14.

44. Lawrence DG, Kuypers HGJM. The functional organization of the motor system in the monkey. II. The effects of lesions of the descending brain-stem pathways. Brain. 1968; 91: 15-36.

45. Dehaene I, Dom R, Martin JJ. Le syndrome «locked-in». Étude clinique de dix cas. Acta Neurol Belg. 1984; 84: 12-20.

46. Reznik M. Neuropathology in seven cases of locked in syndrome. J Neurol Sci. 1983; 60: 67-78.

47. Munschauer FE, Mador J, Ahuja A, et al. Selective paralysis of voluntary but not limbically influenced automatic respiration. Arch Neurol. 1991; 48: 1190-1192.

48. Poeck K. Pathological laughter and crying. In Editor: Handbook of Clinical Neurology vol 1 (45): Clinical Neuropsychology. Elsevier Science Publishers. 1985.

49. Wiesendanger M, DesmedtJE. Some aspects of pyramidal tract function in primates In Editor: New Developments in Electromyography and Clinical Neurophysiology volume 3: Human Reflexes: Pathophysiology of Motor Systems Methodology of Human Reflexes. Basel: Karger. 1973.

50. Gowers WR. "Athetosis" and post hemiplegic disorders of movement. Med Chir Trans. 1876; 59: 271-326.

51. Dooling EC, Adams RD. The pathological anatomy of posthemiplegic athetosis. Brain. 1975; 98: 29-48.

52. ten Donkelaar HJ. Clinical Neuroanatomy. Brain Circuitry and its Disorders. New York Springer. 2011. 